OPEN ACCESS

Edited by:

Liliane Ruess,

Humboldt-Universität zu Berlin,

Germany

Reviewed by:

Blake Matthews,

Swiss Federal Institute of Aquatic Science and Technology (Eawag),

Switzerland

Christian E. W. Steinberg, Humboldt-Universität zu Berlin,

Germany

*Correspondence:

Elina T. Peltomaa

elina.peltomaa@helsinki.fi

Specialty section:

This article was submitted to

Population and Evolutionary

Dynamics,

a section of the journa

Frontiers in Ecology and Evolution

Received: 02 May 2017 Accepted: 29 September 2017

Published: 17 October 2017

Citation:

Peltomaa ET, Aalto SL, Vuorio KM and Taipale SJ (2017) The Importance of Phytoplankton Biomolecule Availability

for Secondary Production.

Front. Ecol. Evol. 5:128

doi: 10.3389/fevo.2017.00128

\section{The Importance of Phytoplankton Biomolecule Availability for Secondary Production}

\author{
Elina T. Peltomaa ${ }^{1,2 *}$, Sanni L. Aalto ${ }^{3}$, Kristiina M. Vuorio $^{4}$ and Sami J. Taipale ${ }^{3}$ \\ ${ }^{1}$ Department of Environmental Sciences, University of Helsinki, Lahti, Finland, ${ }^{2}$ Lammi Biological Station, University of \\ Helsinki, Lammi, Finland, ${ }^{3}$ Department of Biological and Environmental Science, University of Jyväskylä, Jyväskylä, Finland, \\ ${ }^{4}$ Freshwater Centre, Finnish Environment Institute (Syke), Helsinki, Finland
}

The growth and reproduction of animals is affected by their access to resources. In aquatic ecosystems, the availability of essential biomolecules for filter-feeding zooplankton depends greatly on phytoplankton. Here, we analyzed the biochemical composition, i.e., the fatty acid, sterol and amino acid profiles and concentrations as well as protein, carbon, nitrogen, and phosphorus content of 17 phytoplankton monocultures representing the seven most abundant phytoplankton classes in boreal and sub-arctic lakes. To examine how the differences in the biochemical composition between phytoplankton classes affect their nutritional quality for consumers, we assessed the performance of Daphnia, on these diets. Furthermore, we defined the most important biomolecules regulating the somatic growth and reproduction of Daphnia, expecting that higher concentrations of certain biomolecules are needed for reproduction than for growth. Finally, we combined these results with phytoplankton field data from over 900 boreal and sub-arctic lakes in order to estimate whether the somatic growth of Daphnia is sterol-limited when the natural phytoplankton communities are cyanobacteria-dominated. Our analysis shows that Daphnia grows best with phytoplankton rich in sterols, $\omega-3$ fatty acids, protein, and amino acids. Their reproduction follows food sterol and $\omega-3$ concentration as well as C:P-ratio being two times higher in Daphnia feeding on cryptophytes than any other diet. Interestingly, we found that a high dietary $\omega-6$ fatty acid concentration decreases both somatic growth and reproduction of Daphnia. When combined with phytoplankton community composition field data, our results indicate that zooplankton is constantly limited by sterols in lakes dominated by cyanobacteria ( $\geq 40 \%$ of total phytoplankton biomass), and that the absence of cryptophytes can severely hinder zooplankton production in nature.

Keywords: nutritional ecology, freshwater food webs, Daphnia, fatty acids, sterols, amino acids, cryptophytes, cyanobacteria

\section{INTRODUCTION}

An organism's metabolism, together with the availability of essential resources, affects its performance. Organic matter generated by autotrophs sustains heterotrophic consumers, but the resource requirements vary depending on the organism. The autotrophic producers need mainly mineral nutrients and simple compounds, whereas consumers require many complex organic 
compounds, which they need to obtain from the diet. In nature, there is often a mismatch between the metabolic requirements of consumers and nutritional quality of producers, and this typically results in reduced somatic growth and reproduction of grazers (Boersma and Elser, 2006; Behmer, 2009; Hessen et al., 2013). Studies on consumer nutritional requirements, especially on the ones linking multiple trophic levels, are needed to understand food web dynamics more thoroughly (Twining et al., 2016).

The aquatic pelagic food webs are mainly based on phytoplankton primary production. Herbivorous zooplankton diet consists of various phytoplankton species, which differ in their grazing resistance (e.g., size, shape, armor, and toxins) and nutritional quality (Taipale et al., 2013, 2016a; Jonasdottir, 2015). The relative carbon $(\mathrm{C})$ and nitrogen $(\mathrm{N})$ contents are more or less the same in phytoplankton and zooplankton, and therefore are not often considered as limiting nutrients for zooplankton (Hessen et al., 2013). In contrast, adequate uptake of phosphorus (P) is crucial for optimal somatic growth and reproduction of zooplankton (Hessen, 2008), and many studies have concluded reduced growth efficiency under P limitation (atomic C:P $>300$; Urabe et al., 1997; Boersma, 2000; Park et al., 2002; Sterner and Elser, 2002; Frost et al., 2005).

Besides being important source for mineral nutrients, phytoplankton provide many essential biomolecules such as, sterols, fatty acids (FAs), and amino acids (AAs) to consumers, which cannot synthesize them adequately de novo (Vance and Vance, 2008; Brett et al., 2009; Martin-Creuzburg et al., 2009). The availability and quality of the biomolecules affects the somatic growth of zooplankton, which is important since the zooplankton body size is directly reflected to its fitness and reproductive output, e.g., the timing of maturity, fecundity, and the survival potential of the offspring (Hart and Bychek, 2011). This is ecologically important because zooplankton have a key position in aquatic food webs by linking the flow of dietary energy and the essential biomolecules from lower (phytoplankton) to upper (fish) trophic levels (Taipale et al., 2016b).

The importance of certain biomolecules on zooplankton performance has already been recognized. Together with many colleagues, the authors of this paper have shown that the FA composition of freshwater zooplankton is very strongly related to that of their diets, and the polyunsaturated fatty acids (PUFAs), particularly the long chain $\omega-3$ FAs like eicosapentaenoic acid

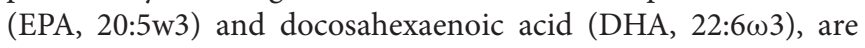
vital for zooplankton growth and reproduction (see e.g., Park et al., 2002; Brett et al., 2006; Martin-Creuzburg et al., 2009; Ravet et al., 2010; Taipale et al., 2011, 2014, 2015; Galloway et al., 2014). Further, it has been shown that high omega-3 $(\omega-3)$ compared to $\omega-6$ PUFA ( $\omega-3: 6$ ratio) is beneficial for Daphnia, but straight negative effects of $\omega-6$ FAs on Daphnia growth or reproduction have not yet been reported (Taipale et al., 2015). The only source of long chain PUFAs in pelagic food webs is phytoplankton whose FA profiles are taxon-specific (Müller-Navarra et al., 2000; von Elert, 2002; Ravet et al., 2003; Taipale et al., 2013). Thus, the availability of FAs in aquatic food webs depends on phytoplankton community composition; for example cryptophytes are rich in EPA that is not synthesized by cyanobacteria or chlorophytes (Taipale et al., 2013; Galloway and Winder, 2015).
The study of Taipale et al. (2016a) describes sterol profiles for several freshwater phytoplankton strains and concludes that in contrary to FA synthesis, their sterol synthesis is in general less related to phylogeny. However, the study of Taipale et al. (2016a) does not evaluate the nutritional quality of sterols for zooplankton, but that is reported by MartinCreuzburg et al. $(2009,2014)$ and Martin-Creuzburg and Von Elert (2004). Cholesterol is the main sterol for cladoceran zooplankton, but they can also utilize phytosterols, which are bioconverted to cholesterol that meets their needs for somatic growth and reproduction (Martin-Creuzburg et al., 2009). However, not all phytosterols are equally good for bioconversion; the cholesterol threshold concentration of sterol limited growth (25\% reduction of $\mathrm{g}_{\infty}$ ) of Daphnia magna is $8.9 \mu \mathrm{g} \mathrm{mg} \mathrm{C} \mathrm{C}^{-1}$, and the supplementing phytosterols are required in concentrations ranging between 3.5 . and $34.3 \mu \mathrm{g}$ $\mathrm{mg} \mathrm{C}^{-1}$ (Martin-Creuzburg et al., 2014). The low threshold phytosterols, i.e., fucosterol, brassicasterol, ergosterol, and stigmasterol, support Daphnia somatic growth more efficiently and already in lower amounts than cholesterol, whereas the high threshold phytosterols, i.e., desmosterol, sitosterol, lathosterol, dihydrocholesterol, and 7-dehydrocholesterol, are needed in higher amounts than cholesterol (Martin-Creuzburg et al., 2014; Supplemental Table 1).

Dietary proteins include AAs, enzymes, and proteins that are required for tissue growth and development. Phytoplankton is in general rich in AAs, but the AA profiles can differ significantly between even closely related species (Brown et al., 1997; Koch et al., 2012). For zooplankton, the essential AAs are considered to be the same as for insects and humans (Supplemental Table 2; Fink et al., 2011). In cladoceran zooplankton, the availability of dietary proteins and essential amino acids (EAAs) has been connected to resting egg production rather than to somatic growth. More precisely, high dietary arginine and histidine have been found to induce the production of subitaneous offspring, whereas the lack of these EAAs has led to sexual resting egg production (Koch et al., 2009, 2012; Fink et al., 2011; Bouchnak and Steinberg, 2014). Therefore, proteins and AAs can be considered as resources affecting the reproductive mode, performance, and population growth of zooplankton in nature.

The current understanding of factors influencing metabolism and the following performance of herbivorous zooplankton results from numerous experiments, which have focused mainly on one or two nutritional components at the same time (Urabe and Watanabe, 1992; Sterner and Schultz, 1998; Müller-Navarra et al., 2000; Becker and Boersma, 2003; Ravet and Brett, 2006). Further, the determination of the diet of the non-selective filterfeeding zooplankton is complex in field conditions and thus many of the studies rely solely on laboratory experiments and lacks attempts to link laboratory results with field observations. Therefore, it is possible that nutritional limitations identified in the laboratory conditions may not apply in nature (Boersma, 2000). However, by knowing the FA, sterol and AA profiles of different phytoplankton taxa and the threshold levels of these biomolecules for zooplankton, it is possible to estimate which biomolecules truly are limiting secondary production in nature. Unfortunately, the threshold levels are species-specific, and thus 
still poorly known for many compounds and consumers (MartinCreuzburg et al., 2014). Nevertheless, the nutritional quality of phytoplankton can be thoroughly examined in controlled feeding experiments if the concentrations of different biomolecules of the food are detected simultaneously.

In this study, we measured the performance of the freshwater keystone filter-feeding zooplankton genus Daphnia, fed on 17 distinct phytoplankton monocultures from 7 classes, typical for boreal and subarctic lakes. We used these lakes as our model ecosystems because they are the most numerous of all lake types on the earth and are estimated to contain at least $80 \%$ of the world's unfrozen freshwater (Schindler, 1998). We analyzed the FA, sterol and AA profiles and concentrations as well as protein, $\mathrm{C}, \mathrm{N}$, and $\mathrm{P}$ content of the phytoplankton strains, and defined the most pronounced biomolecules regulating the somatic growth and reproduction of Daphnia. Based on our modeling results, phytoplankton sterol profiles (this study and Taipale et al., 2016a), sterol threshold levels of Daphnia (Martin-Creuzburg et al., 2014), and phytoplankton community composition data from 907 boreal and sub-arctic lakes, we estimated if Daphnia are limited by sterols in these lakes, and can the presence of certain phytoplankton taxa indicate zooplankton sterol limitation. Our study hypothesis were: (1) the biochemical composition and the nutritional quality is phytoplankton class-specific, (2) the growth and reproduction of Daphnia is related to the nutritional quality of the diet, (3) phosphorus, $\omega-3$ FAs and sterols are the most important biomolecules for Daphnia, (4) higher concentrations of certain biomolecules are needed for reproduction than for growth, and (5) the somatic growth of Daphnia is sterol-limited in lakes dominated by cyanobacteria.

\section{MATERIALS AND METHODS}

\section{Culture Conditions and Growth and Reproduction Experiments}

For the experimental part of this study, 15 strains of planktonic algae and two stains of planktonic cyanobacteria (Table 1) were grown in MWC-medium (Guillard and Lorenzen, 1972) in $600 \mathrm{~mL}$ plastic tissue culture flasks. Each strain had two replicates, which were kept in $+18^{\circ} \mathrm{C}$ and under a light:dark cycle of $16: 8 \mathrm{~h}$. The intensity of the illumination was selected based on known preferences, so that strains belonging to the same class were exposed to similar light levels between 10 and $80 \mu \mathrm{mol}$ quanta $\mathrm{s}^{-1} \mathrm{~m}^{-2}$ in order to ensure that the possible differences in biomolecule profiles were due to the genetics and not to growth conditions. The samples for elemental and biomolecule analysis were taken from exponentially growing stocks, and similarly, samples from the zooplankton feeding experiments were taken from exponentially growing cultures.

As our model zooplankton, we used the filter-feeding Daphnia magna, which are the most commonly used Daphnia-species in laboratory experiments (Lampert, 2006). The stock cultures of Daphnia were maintained in phosphorus-free ADaM-medium (Klüttgen et al., 1994) at room temperature $\left(+20^{\circ} \mathrm{C}\right)$ and fed with chlorophyte Acutodesmus sp. The growth and reproduction experiments were done with second or third-clutch juveniles of Daphnia hatched within $16 \mathrm{~h}$ prior to the experiment. The juveniles were collected into a glass jar filled with fresh ADaMmedium, after which they were individually grown in $50 \mathrm{~mL}$ glass beakers and fed with pure cultures of algae or cyanobacteria. Each treatment had six replicates. For 14 days, the animals were fed every other day with fresh food and transferred into new beakers every time they were fed from day 4 onwards. They were kept under saturating food concentrations in terms of carbon, i.e., the carbon content of the feed was $1.5 \mathrm{mg} \mathrm{C} \mathrm{L}^{-1}$ at day $0,2 \mathrm{mg} \mathrm{C} \mathrm{L}^{-1}$ at day 2 and $5 \mathrm{mg} \mathrm{C} \mathrm{L}^{-1}$ on day 4 and onwards. The offspring born during the experiment were counted and removed within $16 \mathrm{~h}$ from hatching. At the end of the experiment, the amount of unhatched eggs was counted under Leica ES2 stereomicroscope (Leica Microsystems, Germany) with total magnification of $30 \times$.

\section{Carbon, Nitrogen, and Phosphorus Analysis}

The proportions of carbon (C\%) and nitrogen (N\%) of phytoplankton were analyzed with Flash 1112 series Element Analyzer (Thermo Fisher Scientific, U.S.A.). Protein content (Protein\%) was calculated by multiplying elemental nitrogen content with 4.78, which is the nitrogen content of phytoplankton proteins (Laurens, 2013). Phytoplankton phosphorus content (P\%) was determined from filtered samples $(20-25 \mathrm{~mL}$, on GF/C glass microfibre filters; Whatman, England), which were dried in an oven $\left(105^{\circ} \mathrm{C}, 4 \mathrm{~h}\right)$. The filters were placed in glass jars and phosphorus was extracted with sulfuric acid. Samples were analyzed with automated discrete photometric analyzer Gallery Plus (Thermo Fisher Scientific).

\section{Fatty Acid, Sterol and Amino Acid Analysis}

Samples for FA, sterol and AA analyses were freeze-dried and stored for no longer than 1 month. The FA analyses followed the protocol published in Taipale et al. (2016a). Shortly, lipids from freeze-dried, homogenized phytoplankton (1-3 mg) were extracted using a chloroform:methanol $2: 1$ mixture at $90^{\circ} \mathrm{C}$. Hexane and sulfuric acid were used for the transesterification of fatty acid methyl esters (FAME). FAMEs were analyzed with a gas chromatograph (Shimadzu Ultra, Japan) equipped with mass detector (GC-MS) and using helium as a carrier gas and an Agilent ${ }^{\circledR}$ (California, U.S.A.) DB-23 column (30 $\mathrm{m} \times 0.25 \mathrm{~mm} \times$ $0.15 \mu \mathrm{m}$ ). Fatty acids were identified by the retention times (RT) and using specific ions.

Sterols were analyzed according Taipale et al. (2016a). Shortly, the extracted lipids were saponified with $\mathrm{KOH}$ at $70^{\circ} \mathrm{C}$, after which they were silylated with $\mathrm{N}, \mathrm{O}$-bis[trimethylsilyltrifluoroacetamide] (BSTFA), trimethylchlorosilane (TMCS) and pyridine at $70^{\circ} \mathrm{C}$. Trimethylsilyl (TMS) derivatives of sterols were analyzed with GC-MS (Shimadzu) equipped with A Phenomenex (Torrance, California, U.S.A.) ZB-5 Guardian column (30 m $\times$ $0.25 \mathrm{~mm} \times 0.25 \mu \mathrm{m})$. Sterols were identified using characteristic ions (Taipale et al., 2016a).

Amino acid sample preparation was done with the commercial kit EZ:faast For Free Physiological Amino Acid Analysis by GC-MS (Phenomenex, Germany). Samples were analyzed with GC-MS (Shimadzu) and a fused silica capillary 


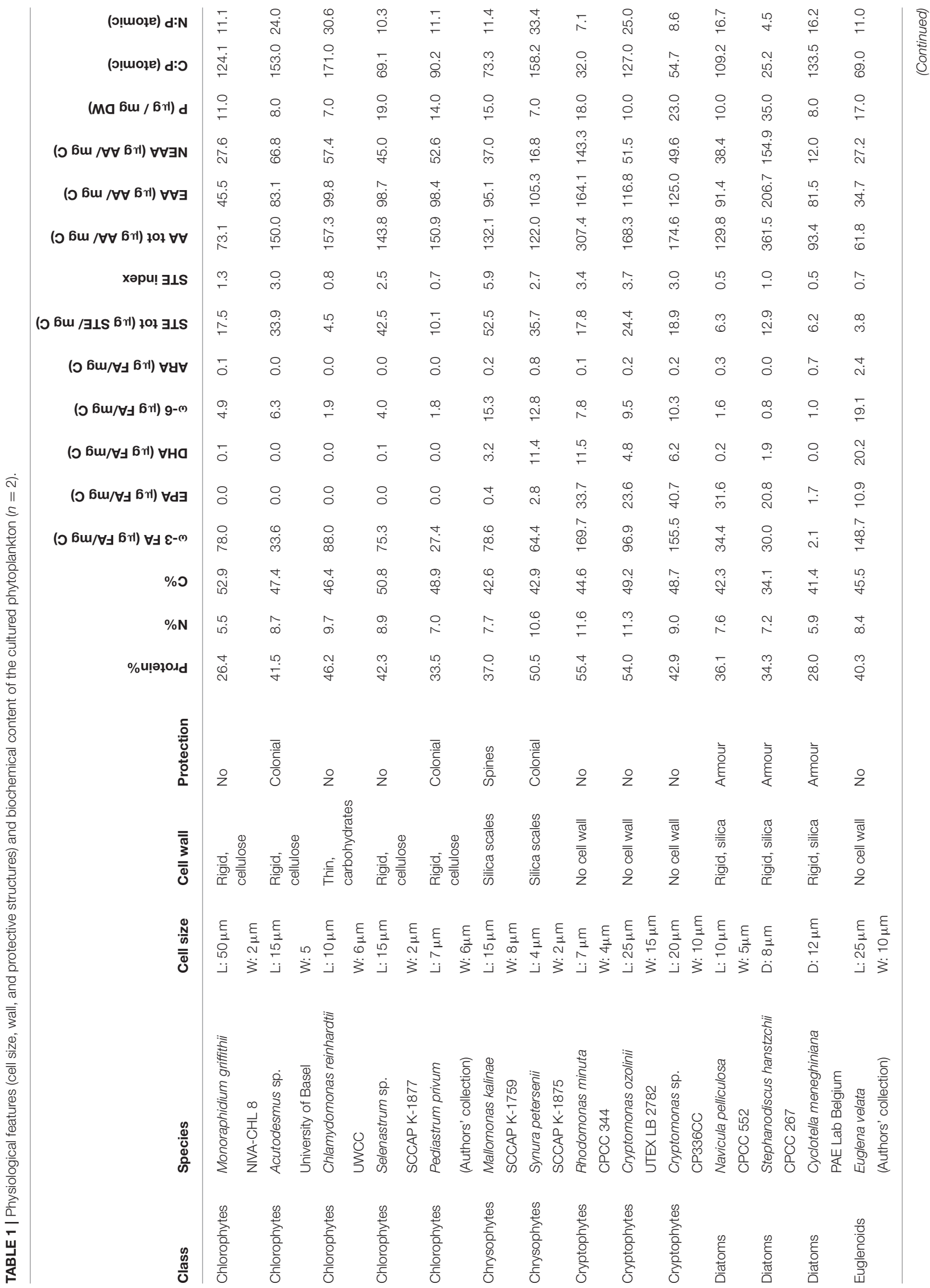




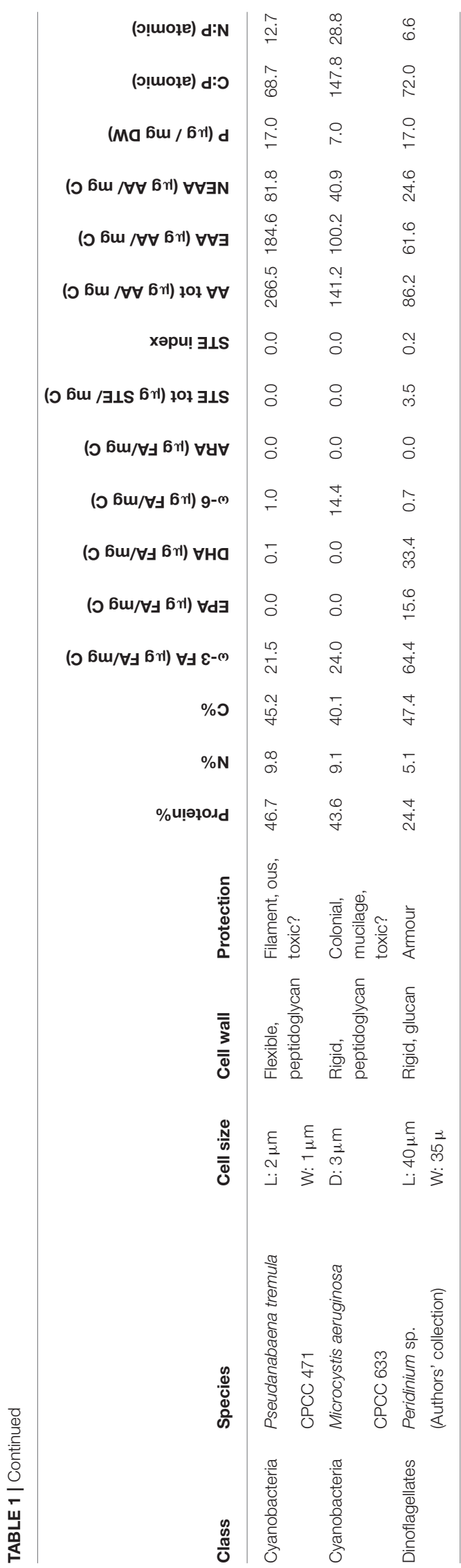

column $(10 \mathrm{~m} \times 0.25 \mathrm{~mm})$, coated with $0.2 \mu \mathrm{m}$ of an unknown stationary phase (ZB-AAA, Phenomenex). Identification was based on the provided EZ:faast library. Due to the properties of the EZ:faast kit, we were able to analyze eight EAAs (valine, leucine, isoleucine, threonine, methionine, phenylalanine, lysine, and histidine), but not arginine or tryptophan. In addition, we were able to quantify nine non-essential amino acids (NEAAs; alanine, glycine, serine, proline, asparagine, glutamic acid, ornithine, glycine-proline and tyrosine).

\section{FIELD DATA AND STEROL-INDEX}

In order to evaluate the availability of dietary sterols and potential sterol limitation of Daphnia in boreal and sub-arctic lakes, we used 9057 phytoplankton community composition samples from 907 lakes registered in the phytoplankton database of the Finnish Environment Institute. The field data consisted only of lakes larger than 30 ha with minimum depth $\geq 2 \mathrm{~m}$. The samples were collected from lakes located from southern to northern Finland, i.e., from boreal and sub-arctic areas, during summer periods (July-August) in 2000-2015. The lakes were sampled at $0-2 \mathrm{~m}$ or $0-4 \mathrm{~m}$ depth. Phytoplankton community composition of each sample is identified to species level when possible using light microscopy (total magnifications of $100-1000 \times)$. The contribution of each species is given as carbon biomass $\left(\mu \mathrm{g} \mathrm{C} \mathrm{L} \mathrm{L}^{-1}\right)$. In order to assess the sterol concentrations in each lake sample, the phytoplankton data was reduced to genus level and the corresponding sterol profiles were obtained from monocultures. Altogether, the monoculture data covered 46 phytoplankton strains from 31 genera and 8 classes, representing the most abundant phytoplankton and/or species that form most of the phytoplankton biomass in boreal lakes (Taipale et al., 2016b). For the unstudied phytoplankton genera we used the sterol profiles of their taxonomically closest relatives.

The threshold values for the sterol-index determinations were obtained from Martin-Creuzburg et al. (2014) who determined dietary threshold concentrations for 10 different phytoplanktonderived sterols. Their determination for sterol limited growth was a $25 \%$ reduction in $g_{\infty}$ (Martin-Creuzburg et al., 2014). We categorized the sterols into two groups, i.e., in low threshold sterols with threshold values similar or even lower than cholesterol and in high threshold sterols with threshold values higher than cholesterol (Supplemental Table 1). The used thresholds were $3.9 \mu \mathrm{g}$ STE $\mathrm{mg} \mathrm{C}^{-1}$ for fucosterol, $5.48 \mu \mathrm{g}$ STE $\mathrm{mg} \mathrm{C}^{-1}$ for brassicasterol, 8.25 $\mu \mathrm{g} \mathrm{STE} \mathrm{mg} \mathrm{C}^{-1}$ for stigmasterol, $15.0 \mu \mathrm{g}$ STE $\mathrm{mg} \mathrm{C}^{-1}$ for camptesterol, and $21.7 \mu \mathrm{g}$ STE $\mathrm{mg} \mathrm{C}^{-1}$ for fungisterol, chondrillasterol, dihydrochondrillasterol and schottenol, and $22.0 \mu \mathrm{g} \mathrm{STE} \mathrm{mg} \mathrm{C}^{-1}$ for b-sitosterol. For untested sterols we used the thresholds of the most similar sterol based on double bonds and carbon chain length.

The analyzed sterol profile (see Supplemental Table 1) of each cultured phytoplankton strain was used for calculating the content (STE; $\mu \mathrm{g}$ STE $\mathrm{mg} \mathrm{C}^{-1}$ ) of each sterol of each phytoplankton species in one lake. The values of species were then used for calculating the overall content of each sterol in one 
lake:

$$
\begin{aligned}
\sum \mu g \text { STE category mg } C^{-1}= & \frac{S T E_{a}{ }^{*} C B M_{a}}{T C M B}+\frac{S T E_{b}{ }^{*} C B M_{b}}{T C M B} \\
& +\ldots+\frac{S T E_{n}{ }^{*} C B M_{n}}{T C M B}
\end{aligned}
$$

where STE is the sterol content ( $\mu \mathrm{g}$ sterol $\mathrm{mg} \mathrm{C}^{-1}$ ) and CBM is the carbon biomass $\left(\mu \mathrm{g} \mathrm{C} \mathrm{L}^{-1}\right.$ ) of each phytoplankton species (a, $\mathrm{b}, \ldots, \mathrm{n})$, and TCBM denotes the total carbon biomass $\left(\mu \mathrm{g} \mathrm{C}^{-1}\right)$ of the corresponding lake sample.

The overall content of each sterol was used to calculate sterol index (STE INDEX) for each lake:

$$
S T E I N D E X=\frac{S T E_{a}^{*}}{T H_{a}}+\frac{S T E_{b}^{*}}{T H_{b}}+\ldots+\frac{S T E_{n}^{*}}{T H_{n}},
$$

where STE* is the overall content ( $\mu \mathrm{g}$ STE category $\mathrm{mg} \mathrm{C}^{-1}$; obtained from Equation 1) of each sterol $(a, b, \ldots, n$; see Supplemental Table 1) in one lake, and TH is the corresponding threshold value ( $\mu$ g sterol $\mathrm{mg} \mathrm{C}^{-1}$ ) for each sterol $(\mathrm{a}, \mathrm{b}, \ldots, \mathrm{n}$; Martin-Creuzburg et al., 2014). Lake sterol index values $<1$ were considered as limiting.

\section{Data Analysis}

For statistical testing of the biochemical class-level similarity of the cultured phytoplankton, the $\omega-3$ and $\omega-6$ FAs, EPA, DHA, EAAs, NEAAs, total AAs, total sterols and sterol-index as well as the $\mathrm{C}, \mathrm{N}$, and protein percentage and $\mathrm{C}: \mathrm{P}$ and $\mathrm{N}: \mathrm{P}-$ ratio data were pooled on a class level. This data was analyzed with one-way analysis of variance (ANOVA) with post-hoc comparisons (Tukey's test). Homogeneity of variances was tested with Levene's test. Differences in the growth and reproduction of zooplankton fed with different phytoplankton classes were tested using Kruskal Wallis test, as the data did not meet normality or homogeneity of variance assumptions.

Generalized linear model (GLM) was used to explore the relationships between Daphnia growth and reproduction and the biochemical variables of the diet, including the total $\omega$ 3 and $\omega-6$ FAs, EPA, DHA, EAAs, NEAAs, total sterols, and C:P -ratio. No transformations were done for the data before GLM. The fit of the model was estimated by interpreting the diagnostic plots (correlation between model residuals and the fitted values, normality of residuals, homoscedasticity of the residuals and possible data outliers). Phosphorus data correlated strongly with C:P-ratio and thus it was excluded from the GLM analysis. The Akaike information criterion (AIC) was used for selecting the minimum adequate model. Model selection was carried out using the step AIC function from R package MASS (Venables and Ripley, 2002), the stepwise search was performed both ways (i.e., backward and forward). The ANOVAs were done with IBM SPSS Statistics 22 (IBM Corp., Armonk, NY, USA) and all the other statistical analyses were conducted in $\mathrm{R}$ ( $\mathrm{R}$ development Core Team, 2017). All phytoplankton and Daphnia data is deposited in Dryad, provisional DOI is 10.5061/dryad.v6p45.

\section{RESULTS}

\section{Biochemical Composition of Phytoplankton}

The proportion of $\mathrm{C}, \mathrm{N}$, and proteins (Figure 1A) varied between the studied phytoplankton classes $(p<0.05)$, but $\mathrm{P}$ concentrations and C:P (Figure 1B) and N:P -ratios were similar (Table 1). Of the studied biomolecules, the amount of total $\omega-3$ FAs varied between phytoplankton classes $(p<0.05)$, and the highest concentrations were found in euglenoids and cryptophytes, whereas diatoms and cyanobacteria had the lowest $\omega-3$ FA concentrations (Table 1, Figure 1C). Among $\omega-3$ FAs, highest EPA and DHA contents were found in cryptophytes, dinoflagellates and euglenoids (Table 1, Figure 1D). The $\omega-6$ FAs were found in all classes, but the concentrations varied significantly $(p<0.05)$ being highest in euglenoids and lowest in dinoflagellates (Table 1, Figure 1C). The high $\omega-6$ FA content of euglenoids was explained by arachidonic acid (ARA, 20:4 $\omega 6$ ), which concentration was extremely high compared to the other taxa $(p<0.001$; Table 1).

The strains differed from each other based on sterol concentrations and the sterol-index (both $p<0.05$, Table 1 ). The total sterol concentration was highest in chrysophytes $(p<0.05)$, which had a lot of both low and high threshold sterols (Figure 1E). However, cryptophytes were also rich in low threshold sterols, and there were no statistical differences between the low threshold sterol concentrations of chrysophytes and cryptophytes (Figure 1E). Chlorophytes, excluding Chlamydomonas and Pediastrum, had a lot of high threshold sterols, which led to fairly high sterol-indexes in chlorophytes as well (> 1; Table 1, Figure 1E). Diatoms had a rather low total sterol concentration, and thus also their sterol-index remained low, as did the indexes of euglenoids and dinoflagellates (Table 1, Figure 1E). Unlike sterols and FAs, the amount of amino acids (total AAs, EAAs, and NEAAs) was more or less the same between classes and most variation was found within the classes rather than between them $(P>0.05$; Table 1, Figure 1F).

\section{Daphnia Growth and Reproduction}

The somatic growth of Daphnia was highest with cryptophyte diet $(p<0.001)$ and retarded when fed with euglenoids or Pseudanabaena (cyanobacteria; Figure 2). There were no statistically significant differences between the growth rates when feeding on chlorophytes, chrysophytes, and diatoms or chrysophytes, diatoms, euglenoids, and cyanobacteria (Kruskal Wallis test, $\mathrm{H}=50, \mathrm{df}=5, p<0.001$, pairwise comparisons, $p>$ 0.05 ; Figure 2A). The highest amount of neonates and eggs was produced when Daphnia were fed with cryptophytes $(p<0.001)$, but also Acutodesmus and Chlamydomonas (chlorophytes) led to fairly high reproduction (Supplemental Table 3). Those Daphnia that were fed with Microcystis (cyanobacteria) or Peridinium (dinoflagellate) died before the 11th experimental day and did not reproduce (Supplemental Table 3). There were no statistical differences between chlorophyte, chrysophyte and diatom diets or between chrysophyte, diatom, euglenophyte and cyanobacteria diets (Kruskal Wallis test, $\mathrm{H}=55, \mathrm{df}=5$, 


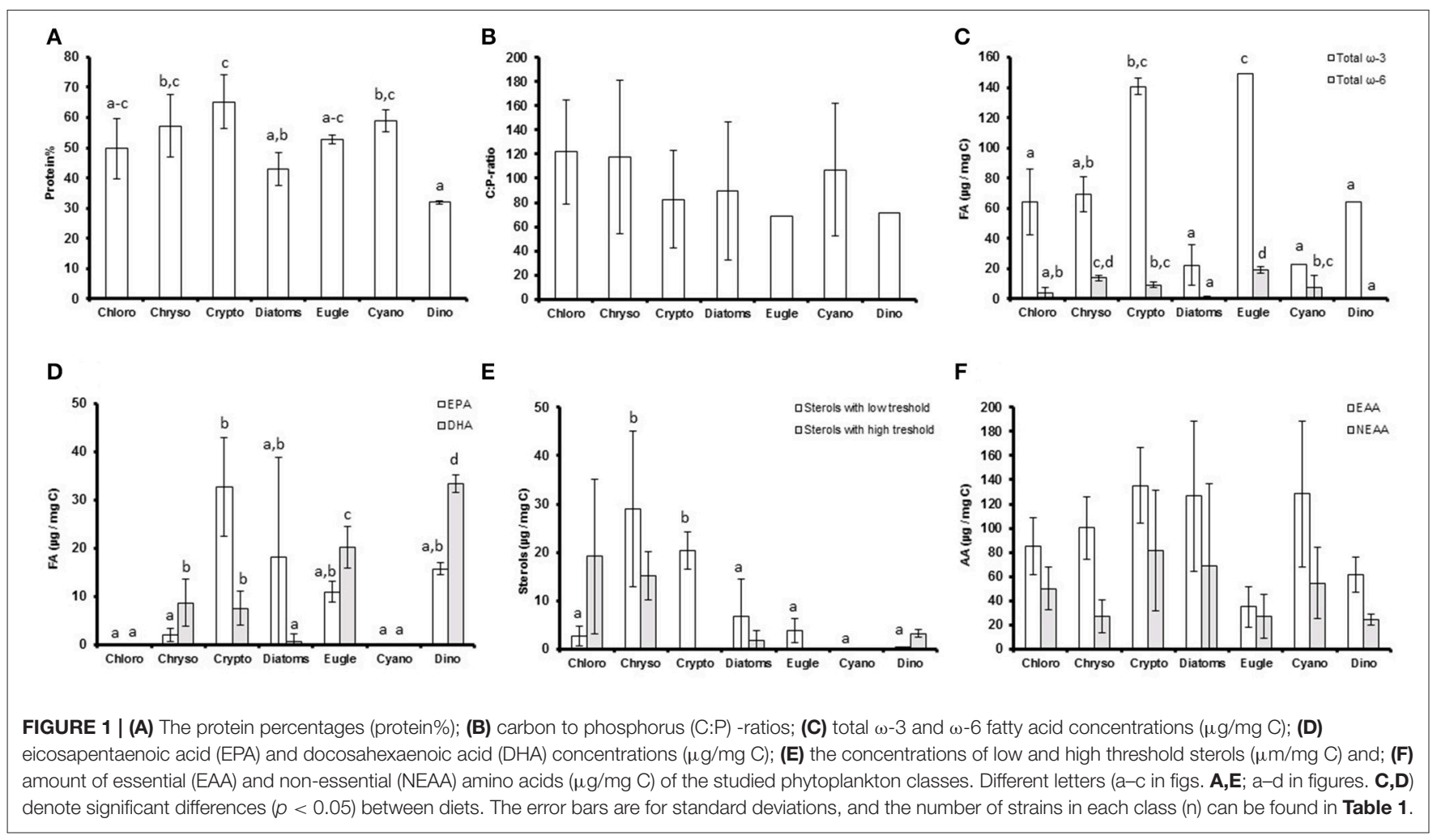

$p<0.001$, pairwise comparisons, $p>0.05$, respectively; Figure 2B).

Based on the effects of the diet on the somatic growth and reproduction of Daphnia, the studied phytoplankton classes could be divided into four categories (Figure 2): poor quality food (cyanobacteria, dinoflagellates, euglenoids) that lack many essentials or are grazing resistant for Daphnia, and thus do not support somatic growth and reproduction; medium quality food (chrysophytes and diatoms) that contains all essentials, but in low quantities and supports Daphnia growth and reproduction to some extent; high quality food (chlorophytes) that has all essentials and supports Daphnia growth and reproduction, and; superior food (cryptophytes) that has all essentials in high quantities and supports fast growth and high reproduction of Daphnia.

According to GLM, high total sterol and EPA content and C:P-ratio and low amount of $\omega-6$ FAs led to high somatic growth (Table 2). However, when poor-quality phytoplankton species, i.e., all cyanobacteria, euglenoids, and dinoflagellates, were removed from the model, the somatic growth followed the amount of NEAAs, $\omega-3$ FAs and protein content (Table 3). High amount of total sterols and $\omega-3$ FAs, high C:P-ratio and low amount of $\omega-6$ FAs led to high reproduction (Table 2), but when cyanobacteria, euglenoids and dinoflagellates were removed from the model, reproduction followed only two food components: $\omega-3$ FAs and C:P-ratio (Table 3).

\section{Food Quality and the Availability of Phytosterols in Lakes}

Based on our data from over 900 boreal and sub-arctic lakes, the average proportion of the nutritionally superior phytoplankton was $19 \%$ (sd \pm 17 ) of the total biomass of phytoplankton, whereas the high quality phytoplankton covered $8 \%$ (sd \pm 9 ), medium quality phytoplankton 39\% (sd \pm $15)$ and poor quality phytoplankton $23 \%(s d \pm 15)$ of the total community. The remaining $11 \%$ ( $\mathrm{sd} \pm 10$ ) was covered by nutritionally unidentified phytoplankton, i.e., those classes that were either not included in our biomolecule analysis or had been categorized as "unidentified species" in the phytoplankton database of the Finnish Environment Institute. However, the phytoplankton community composition varied significantly between the lakes, mainly following the water color (dissolved organic matter concentration) and phosphorus concentration (more detailed phytoplankton data published in Taipale et al., 2016b), and thus the average proportions are only suggestive.

The calculations of phytosterol concentrations in over 9,000 field samples indicate that in $70 \%$ of the boreal and subarctic lakes the somatic growth of Daphnia is not limited by phytosterol availability (sterol-index > 1). However, Daphnia are occasionally sterol limited in 19\%, and continuously sterol limited in $11 \%$ of these lakes (sterol-index $<1$; Figure 3A). Sterol limitation is most common in the cyanobacteria-dominated lakes, and in lakes where $\geq 40 \%$ of the phytoplankton biomass 

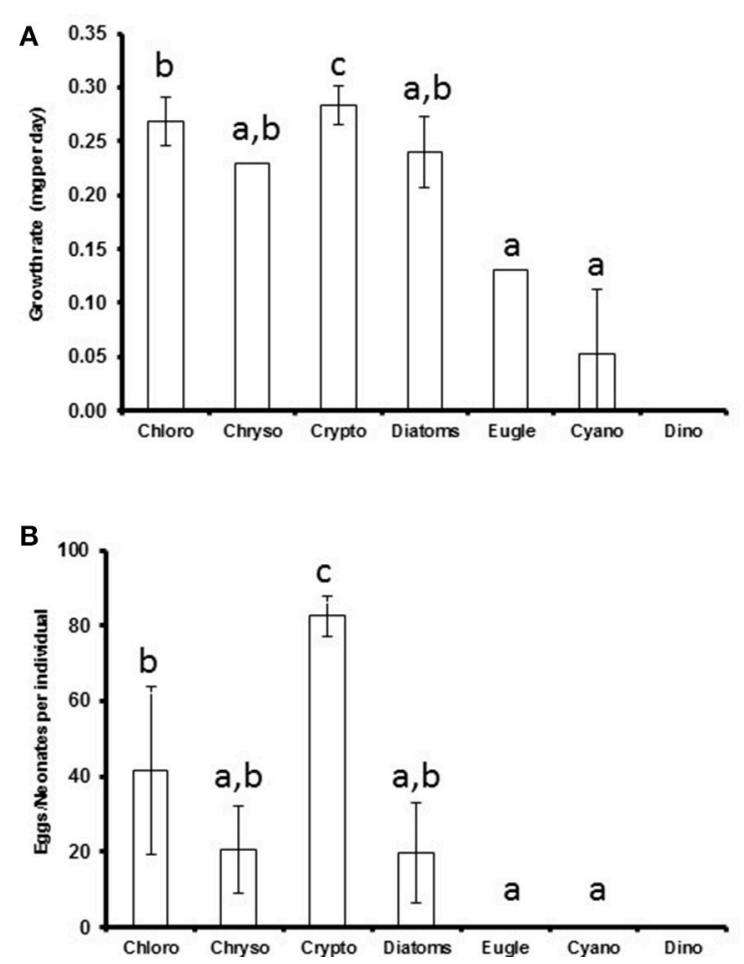

FIGURE 2 | The average phytoplankton class-specific growth rate (A) and clutch size (B) of Daphnia. Cryptophytes, rich in all studied biomolecules, could be classified as superior food for Daphnia in terms of both somatic growth and reproduction, whereas chlorophytes were high quality food, chrysophytes, and diatoms medium quality food and cyanobacteria, dinoflagellates, and euglenoids poor quality food. Different letters $(a-c)$ denote significant differences $(p<0.05)$ between diets. The error bars are for standard deviations.

consists of cyanobacteria, the sterol-index was found to be permanently too low, i.e., $<1\left(r^{2}=0.45\right.$; Figure $\left.3 B\right)$.

\section{DISCUSSION}

Here, we studied the effect of different phytoplankton diets on the somatic growth and reproduction of filter-feeding Daphnia that occupy a central position in aquatic food webs consuming phytoplankton and being consumed by fish. In our experimental setup, the quantity of the offered food in terms of carbon was saturating (Müller-Navarra et al., 2000), and thus we could focus on the nutritional quality of different phytoplankton taxa. We hypothesized that the biochemical composition and the nutritional quality is phytoplankton class-spesific, and that Daphnia growth and reproduction is related to the nutritional quality of their diet (phytoplankton). In accordance with our hypothesis, we found that cryptophytes are rich in all observed biomolecules, and support significantly higher somatic growth and faster reproduction than any other phytoplankton class, making them superior food for Daphnia. This is not the first study that highlights cryptophytes as food sources for daphnids (see e.g., Ahlgren et al., 1990; Martin-Creuzburg and Von Elert, 2009; Brzezinski et al., 2010), but this is the first one that shows
TABLE 2 | GLM results for Daphnia growth and reproduction when all of studied phytoplankton strains were included in analysis.

\begin{tabular}{|c|c|c|c|c|c|}
\hline & & Estimate & $S D$ & $t$-values & $P$ \\
\hline \multirow[t]{2}{*}{ Growth } & Intercept & 0.1347 & 0.042 & 3.165 & 0.016 \\
\hline & Sterols & 0.0033 & 0.001 & 6.050 & $<0.001$ \\
\hline $\mathrm{AlC}$ & EAA & -0.0005 & 0.000 & -1.865 & 0.104 \\
\hline \multirow[t]{5}{*}{-59.76} & NEAA & 0.0006 & 0.000 & 1.994 & 0.086 \\
\hline & $\omega-3$ & 0.0004 & 0.000 & 1.768 & 0.120 \\
\hline & EPA & 0.0014 & 0.000 & 2.991 & 0.020 \\
\hline & $\omega-6$ & -0.0090 & 0.002 & -4.244 & 0.004 \\
\hline & C:P & 0.0006 & 0.000 & 3.052 & 0.019 \\
\hline \multirow[t]{2}{*}{ Reproduction } & Intercept & -52.146 & 20.490 & -2.545 & 0.034 \\
\hline & Sterols & 1.0189 & 0.326 & 3.13 & 0.014 \\
\hline $\mathrm{AlC}$ & NEAA & 0.1826 & 0.140 & 1.301 & 0.229 \\
\hline \multirow[t]{4}{*}{131.43} & $\omega-3$ & 0.4047 & 0.131 & 3.085 & 0.015 \\
\hline & EPA & 0.4737 & 0.273 & 1.736 & 0.121 \\
\hline & $\omega-6$ & -2.9849 & 1.241 & -2.406 & 0.043 \\
\hline & C:P & 0.3116 & 0.121 & 2.57 & 0.033 \\
\hline
\end{tabular}

The statistically significant results $(p<0.05)$ are written in bold.

TABLE 3 | GLM results for growth and reproduction of Daphnia fed with medium, high and superior quality phytoplankton, i.e., excluding cyanobacteria, dinoflagellates, and euglenoids.

\begin{tabular}{|c|c|c|c|c|c|}
\hline & & Estimate & SD & $t$-value & $P$ \\
\hline Growth & Intercept & 0.1709 & 0.022 & 7.848 & $<0.001$ \\
\hline \multirow[t]{6}{*}{$\mathrm{AIC}-68.10$} & Protein \% & 0.0017 & 0.000 & 3.818 & 0.009 \\
\hline & Sterols & 0.0008 & 0.000 & 1.794 & 0.123 \\
\hline & EAA & -0.0005 & 0.000 & -2.174 & 0.073 \\
\hline & NEAA & 0.0008 & 0.000 & 3.123 & 0.021 \\
\hline & $\omega-3$ & 0.0003 & 0.000 & 2.798 & 0.031 \\
\hline & $\omega-6$ & -0.0043 & 0.002 & -2.305 & 0.061 \\
\hline Reproduction & Intercept & -72.41 & 29.57 & -2.449 & 0.049 \\
\hline \multirow[t]{6}{*}{ AIC 115.68} & Sterols & 1.5690 & 0.711 & 2.207 & 0.069 \\
\hline & NEAA & 0.1584 & 0.151 & 1.047 & 0.335 \\
\hline & $\omega-3$ & 0.4366 & 0.143 & 3.060 & 0.022 \\
\hline & EPA & 0.7209 & 0.376 & 1.916 & 0.104 \\
\hline & $\omega-6$ & -4.4233 & 2.310 & -1.915 & 0.104 \\
\hline & C:P & 0.4126 & 0.164 & 2.510 & 0.046 \\
\hline
\end{tabular}

The statistically significant results $(p<0.05)$ are written in bold.

how optimal they are regarding all dietary requirements. Since most of the phytoplankton community in boreal and sub-arctic lakes is made by medium (average $39 \%$ ) or poor $(23 \%)$ quality taxa, cryptophytes can significantly improve the nutritional status of zooplankton when present. In temperate, boreal and subarctic lakes, cryptophytes are among the first phytoplankton species occurring in high densities in spring after ice-out (e.g., De Huszar et al., 1998; Reynolds, 2006; Peltomaa et al., 2013). Our results on cryptophyte superiority as food suggest that they boost the zooplankton production significantly at a time when phytoplankton production and biomass are generally low. Because of the great importance of Daphnia in aquatic food 


\section{A}

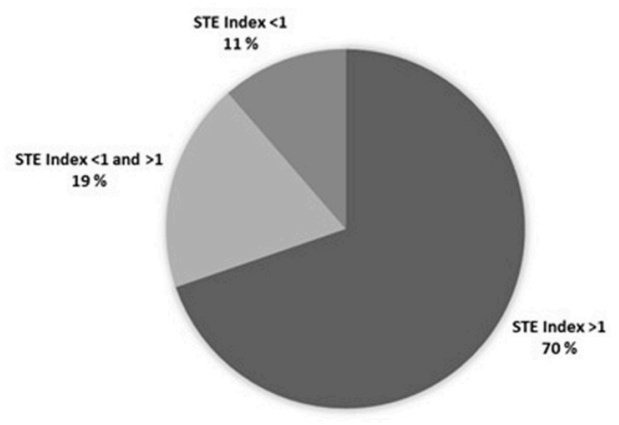

B

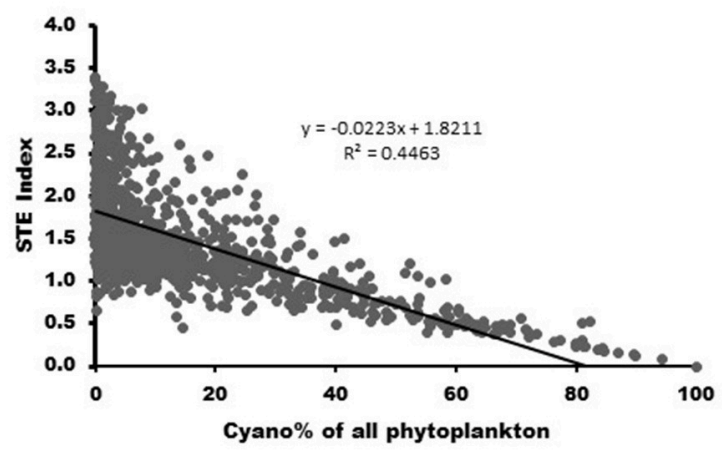

FIGURE 3 | (A) The proportions of sterol sufficient (STE index $>1$ ), occasionally sterol limited (STE index $<1$ and $>1$ ) and permanently sterol limited (STE index $>1$ ) lakes in boreal and sub-arctic area (based on dataset of 9057 phytoplankton samples from 907 lakes). (B) Sterol limitation (STE index $<1$ ) occurs in lakes where $\geq 40 \%$ of the phytoplankton biomass consisted of cyanobacteria.

webs, it is especially likely that the effect of the early-spring cryptophyte abundance can cascade up to freshly hatched fish juveniles (Kerfoot et al., 1988; Turner, 2004; Taipale et al., 2016b), and thus be reflected to the whole food web.

Based on the previous studies (e.g., Brett et al., 2006; Hessen, 2008; Martin-Creuzburg et al., 2009; Ravet et al., 2010; Taipale et al., 2011, 2014, 2015), we expected phosphorus, $\omega$ 3 FAs and sterols being the most important biomolecules for Daphnia performance. In addition to cryptophytes, chlorophytes, chrysophytes, and diatoms had adequate concentrations of these biomolecules and thus resulted in high somatic growth of Daphnia. However, their neonate production capacity varied greatly, which was related to diet $\omega-3$ FA content and C:P-ratio. Since similar variation was not seen in somatic growth, we believe that higher concentrations of certain biomolecules are needed for reproduction than growth (Hypothesis 4). The importance of $\omega-3$ FAs and C:P-ratio for Daphnia somatic growth has been previously reported by e.g., Park et al. (2002), who estimated that $70 \%$ of the variations in Daphnia growth rates were explained by these two factors. However, like in most studies on biomolecules, Park et al. (2002) focused only on FAs and did not study for example sterols or AAs. Thus, they could not rule out the possible effects of other biomolecules on their results. Here, we included all major biomolecule groups into our analysis and still found $\omega-3$ content and C:P-ratio as the most important factors in controlling both somatic growth and offspring production of Daphnia.

The GLM modeling for the whole dataset, including the grazing resistant species, showed the crucial importance of sterols in Daphnia growth and reproduction, which could not be fulfilled by all of the studied phytoplankton taxa. The importance of sterols on Daphnia growth has been previously underlined by Martin-Creuzburg et al. (e.g., Martin-Creuzburg et al., 2008, 2014), who showed that phytosterols differ in their efficiency to support the somatic growth of Daphnia (Martin-Creuzburg et al., 2014). They also reported that the somatic growth of Daphnia is co-limited by sterols and EPA (Martin-Creuzburg et al., 2008). Our results agree with their observations, and further emphasizes the role of these biomolecules in Daphnia reproduction. However, according to our data, the reproduction of Daphnia is dependent on total $\omega-3$ FAs rather than only on EPA.

It has been shown earlier that in natural Daphnia populations high $\omega-6: 3$ ratio indicates poor nutritional condition and growth (Taipale et al., 2015). We found that high dietary $\omega-6$ FAs actually decreased the somatic growth and offspring production of Daphnia. To our knowledge, our study is the first to report direct negative effects of $\omega-6$ FAs on Daphnia or any zooplankton species, and these kinds of observations are scarce for invertebrates or aquatic organisms in general. However, in terrestrial environments it is shown that a high pollen $\omega-6: 3$ ratio can cause the collapse of honey bee colonies, since the relative dietary shortage of $\omega-3$ compared to $\omega-6$ decreases bee health and greatly reduces their learning abilities (Arien et al., 2015). Further, excess dietary gain of $\omega-6$ FAs is known to promote cardiovascular disease, cancer, and inflammatory and autoimmune diseases in humans (Simopoulos, 2008). Together these observations indicate that high dietary $\omega-6$ FAs may have negative effects on the performance of animals in general. In humans it has also been shown that excess consumption $\omega$ 6 FAs reduces the conversion of short chain $\omega-3$ FA alphalinolenic acid (ALA; 18:3 $\omega-3$ ) to long chain EPA and DHA by $40-50 \%$ (Gester, 1998). If this holds for Daphnia too, the reduction can be very significant considering that only minor proportion ( $2 \%$ of the total gain) of ALA is normally transferred to long chain $\omega-3$ FAs in Daphnia (Goulden and Place, 1993). Thus, high $\omega-6$ FA gain can reduce the nutritional quality of otherwise high-quality phytoplankton, such as, chrysophytes.

Compared to mineral stoichiometry and FAs, AAs have been largely neglected in the nutritional studies in aquatic ecology. It has, however, been previously reported that EAA and protein deficiencies trigger the induction of sexual reproduction in cladoceran zooplankton, leading to stronger effect on offspring production and population size than on somatic growth (Koch et al., 2009, 2012; Fink et al., 2011; Bouchnak and Steinberg, 2014). In our study, the protein content, as well as the amount of NEAA, boosted the somatic growth of Daphnia when sterols were adequate (see GLM results on Table 3), but direct connections between proteins, EAAs or NEAAs and reproduction could not be detected. 
The quality of food can be determined in several ways, and a theoretically high nutritional quality of phytoplankton does not always mean high support of zooplankton production, but the actual availability of phytoplankton-derived biomolecules goes hand in hand with their grazing resistance (van Donk et al., 1997; De Mott et al., 1998). Thus, despite of high $\omega-3$, AA, and protein content of dinoflagellates, all Daphnia in our experiment died when fed with Peridinium. This was most probably due to grazing resistance, as these dinoflagellates are fairly large in size and heavily armored thus being unsuitable as food items for the newly hatched Daphnia that we used in our experiment. Some freshwater dinoflagellates are also known to be toxic, and since we did not make toxicity tests, this option cannot be ruled out (Rengefors and LeGrand, 2001). Similarly to Peridinium, our Euglena (euglenoid) was rich in desired biomolecules, especially in $\omega-3$ FAs and proteins, but still Daphnia were not able to reproduce on this diet and also their growth was retarded. We cannot fully explain why this happened, Euglena possesses no cell wall and they are not reported to have other protective structures or produce toxins either. However, we repeated this part of the experiment and got the same result several times. The lethality of Microcystis to Daphnia for their part was probably due to either toxins or morphology. In nature, Microcystis live in large colonies, in a form that can prevent zooplankton grazing. However, when cultured for long, the colonial form changes into mucilage-surrounded single cells or few-cell colonies. This had happened to our Microcystis culture too, and thus we assume that our Microcystis was either toxic or the cells were protected from grazing by the mucilage. Due to their inadequate ability to support Daphnia performance, we categorized cyanobacteria, dinoflagellates, and euglenoids as poor quality food items.

The field part of our study focused on sterols in boreal and sub-arctic lakes, where eutrophication and the resulting increase of cyanobacterial biomass has already been shown to decrease EPA and DHA concentrations in seston, with effects reflecting up to fish and reducing the nutritional quality of fish to humans (Taipale et al., 2016b). We expected the somatic growth of Daphnia being sterol-limited in lakes dominated by cyanobacteria. Indeed, even though our data from over 900 lakes showed that in most (70\%) of these lakes, phytoplankton sterol supply is sufficient for supporting normal somatic growth of Daphnia, in eutrophic lakes characterized by relatively high ( $\geq 40 \%$ of the total) cyanobacterial biomass, Daphnia growth was found to be constantly limited by sterols. This

\section{REFERENCES}

Ahlgren, G., Lundstedt, L., Brett, M. T., and Forsberg, C. (1990). Lipid composition and food quality of some freshwater phytoplankton for cladoceran zooplankters. J. Plank. Res. 12, 809-818. doi: 10.1093/plankt/12.4.809

Arien, Y., Dagb, A., Zarchina, S., Mascia, T., and Shafira, S. (2015). Omega3 deficiency impairs honey bee learning. Proc. Natl. Acad. Sci. U.S.A. 112, 15761-15766. doi: 10.1073/pnas.1517375112

Becker, C., and Boersma, M. (2003). Resource quality effects on life histories of Daphnia. Limnol. Oceanogr. 48, 700-706. doi: 10.4319/lo.2003.48. 2.0700 is due to either cyanobacteria lacking sterols or high quality phytoplankton taxa being replaced by cyanobacteria in the eutrophic lakes. Furthermore, sterols are also required for reproduction (Martin-Creuzburg and Von Elert, 2004). Thus, our field results indicate that reproduction is also sterol limited in cyanobacteria-dominated lakes. This means that the ongoing human-induced eutrophication and climate change, causing shift in the phytoplankton community composition toward the dominance of cyanobacteria (Paerl and Paul, 2012; Sukenik et al., 2015), has major ecological effects on the aquatic food webs through increased sterol, EPA and DHA shortage that will limit secondary production and be reflected further on planktivorous fish and higher predators (Taipale et al., 2016b).

In conclusion, we show that the nutritional quality of phytoplankton depends on several biomolecules, some of which are present in high amounts only in one edible phytoplankton class, cryptophytes. Further, our experiments highlight the importance of high quality phytoplankton diet for zooplankton reproduction, and the field data demonstrates the dangers of the ongoing environmental changes on the primary producersecondary producer-continuum, with possible negative effects on the higher trophic levels of the aquatic food webs.

\section{AUTHOR CONTRIBUTIONS}

EP and ST designed the study and performed the laboratory analyses and the feeding experiments. SA analyzed the feeding experiment data. KV analyzed the field data. All authors wrote the paper.

\section{ACKNOWLEDGMENTS}

The authors are very grateful to Mrs. Penny Sleeth for editing the English of this manuscript, and thank the two reviewers whose appropriate commentary strengthened the manuscript. This research was supported by the Academy of Finland research grant 276268 awarded to EP, 260797 awarded to Marja Tiirola and 263472 awarded to KV.

\section{SUPPLEMENTARY MATERIAL}

The Supplementary Material for this article can be found online at: https://www.frontiersin.org/articles/10.3389/fevo. 2017.00128/full\#supplementary-material

Behmer, S. T. (2009). Insect herbivore nutrient regulation. Annu. Rev. Entomol. 54, 165-187. doi: 10.1146/annurev.ento.54.110807.090537

Boersma, M. (2000). The nutritional quality of P-limited algae for Daphnia. Limnol. Oceanogr. 45, 1157-1161. doi: 10.4319/lo.2000.45. 5.1157

Boersma, M., and Elser, J. J. (2006). Too much of a good thing: on stoichiometrically balanced diets and maximal growth. Ecology 87, 1325-1330. doi: 10.1890/0012-9658(2006)87[1325:TMOAGT]2.0.CO;2

Bouchnak, R., and Steinberg, C. E. W. (2014). Algal diets and natural xenobiotics impact energy allocation in cladocerans. II. Moina macrophora and Moina micrura. Limnologica 44, 23-31. doi: 10.1016/j.limno.2013.06.002 
Brett, M. T., Kainz, M. J., Taipale, S. J., and Seshana, H. (2009). Phytoplankton, not allochthonous carbon, sustains herbivorous zooplankton production. Proc. Natl. Acad. Sci. U.S.A. 106, 21197-21201. doi: 10.1073/pnas.0904129106

Brett, M. T., Müller-Navarra, D. C., Ballantyne, A. P., Ravet, J. L., and Goldman, C. R. (2006). Daphnia fatty acid composition reflects that of their diet. Limnol. Oceanogr. 51, 2428-2437. doi: 10.4319/lo.2006.51.5.2428

Brown, M. R., Jefferey, S. W., Volkman, J. K., and Dunstan, G. A. (1997), Nutritional properties of microalgae for mariculture. Aquaculture 151, 315-331. doi: 10.1016/S0044-8486(96)01501-3

Brzezinski, T., Dawidowicz, P., and Von Elert, E. (2010). The role of food quality in clonal succession in Daphnia: an experimental test. Oecologia 164, 379-388. doi: 10.1007/s00442-010-1662-9

De Huszar, M., Lucia, V., and Caraco, N. (1998). The relationship between phytoplankton composition and physical-chemical variables: a comparison of taxonomic and morphological-functional descriptors in six temperate lakes. Freshw. Biol. 40, 679-696. doi: 10.1046/j.1365-2427.1998.00369.x

De Mott, W. R., Gulati, R. D., and Siewertsen, K. (1998). Effects of phosphorusdeficient diets on the carbon and phosphorus balance of Daphnia magna. Limnol. Oceanogr. 43, 1147-1161. doi: 10.4319/lo.1998.43.6.1147

Fink, P., Pflitsch, C., and Marin, K. (2011). Dietary essential amino acids affect the reproductions of the keystone herbivore Daphnia pulex. PLoS ONE 6:e28498. doi: 10.1371/journal.pone.0028498

Frost, P. C., Evans-White, M., and Finkel, Z. (2005). Are you what you eat? Physiological constraints on organismal stoichiometry in an elementally imbalanced world. Oikos 1, 18-28. doi: 10.1111/j.0030-1299.2005.14049.x

Galloway, A. W. E., and Winder, M. (2015). Partitioning the relative importance of phylogeny and environmental conditions on phytoplankton fatty acids. PLoS ONE 10:e0130053. doi: 10.1371/journal.pone.0130053

Galloway, A. W. E., Taipale, S. J., Hiltunen, M., Peltomaa, E., Standberg, U., Brett, M., et al. (2014). Diet specific biomarkers show that high-quality phytoplankton fuels herbivorous zooplankton in large boreal lakes. Freshw. Biol. 59, 1902-1915. doi: 10.1111/fwb.12394

Gester, H. (1998). Can adults adequately convert alpha-linolenic acid (18:3n-3) to eicosapentaenoic acid (20:5n-3) and docosahexaenoic acid (22:6n-3)? Int. J. Vitam. Nutr. Res. 68, 159-173.

Goulden, C. E., and Place, A. R. (1993). Lipid accumulation and allocation in daphniid cladocera. Bull. Mar. Sci. 53, 106-114.

Guillard, R. R. L., and Lorenzen, C. J. (1972). Yellowgreen algae with chlorophyllide. J. Phycol. 8, 10-14.

Hart, R. C., and Bychek, E. A. (2011). Body size in freshwater planktonic crustaceans: an overview of extrinsic determinants and modifying influences of biotic interactions. Hydrobiologia 668, 61-108. doi: 10.1007/s10750-010-0400-y

Hessen, D. O. (2008). Efficiency, energy and stoichiometry in pelacig food webs; reciprocal roles of food quality and food quantity. Freshw. Rev. 1, 43-57. doi: 10.1608/FRJ-1.1.3

Hessen, D. O., Elser, J. J., Sterner, R. W., and Urabe, J. (2013). Ecological stoichiometry: an elementary approach using basic principles. Limnol. Oceanogr. 58, 2219-2236. doi: 10.4319/lo.2013.58.6.2219

Jonasdottir, S. (2015). A Journey from Light into Darkness. Fatty Acids in the Marine Ecosystem: from Photosynthesis to Copepod Lipids and Sequestration. Doctoral thesis, Technical University of Denmark.

Kerfoot, W. C., Levitan, C., and DeMott, W. (1988). Daphnia-phytoplankton interactions: density-dependent shifts in resource quality. Ecology 69, 1806-1825. doi: 10.2307/1941159

Klüttgen, B., Dülmer, U., Engels, M., and Ratte, H. T. (1994). ADaM, an artificial freshwater for the culture of zooplankton. Water Res. 28, 743-746. doi: 10.1016/0043-1354(94)90157-0

Koch, U., Martin-Creuzburg, M., Grossart, H.-P., and Straile, D. (2012). Differences in the amino acid content of four green algae and their impact on the reproductive mode of Daphnia pulex. Fundam. Appl. Limnol. 181, 327-336. doi: 10.1127/1863-9135/2012/0396

Koch, U., Von Elert, E., and Straile, D. (2009). Food quality triggers the reproductive mode in the cyclical parthenogen Daphnia (Cladocera). Oecologia 159, 317-324. doi: 10.1007/s00442-008-1216-6

Lampert, W. (2006). Daphnia: model herbivore, predator and prey. Pol. J. Ecol. 54, 607-620.

Laurens, L. M. L. (2013). Summative Mass Analysis of Algal Biomass - Integration of Analytical Procedures Laboratory Analytical Procedure (LAP). Technical Report
NREL/TP-5100-60943, National Renewable Energy Laboratory, Denver West Parkway, Golden (Revised December 2015).

Martin-Creuzburg, D., and Von Elert, E. (2004). Impact of 10 dietary sterols on growth and reproduction of Daphnia galeata. J. Chem. Ecol. 3, 483-500. doi: 10.1023/B:JOEC.0000018624.94689.95

Martin-Creuzburg, D., and Von Elert, E. (2009). Good food versus bad food: the role of sterols and polyunsaturated fatty acids in determining growth and reproduction of Daphnia magna. Aquat. Ecol. 43, 943-950. doi: 10.1007/s10452-009-9239-6

Martin-Creuzburg, D., Oexle, S., and Wacker, A. (2014). Thresholds for sterollimited growth of Daphnia magna: a comparative approach using 10 different sterols. J. Chem. Ecol. 40, 1039-1050. doi: 10.1007/s10886-014-0486-1

Martin-Creuzburg, D., Sperfeld, E., and Wacker, A. (2009). Colimitation of a freshwater herbivore by sterols and polyunsaturated fatty acids. Proc. R. Soc. B 276, 1805-1814. doi: 10.1098/rspb.2008.1540

Martin-Creuzburg, D., Von Elert, E., and Hoffman, K. H. (2008). Nutritional constraints at the cyanobacteria-Daphnia magna interface: the role of sterols. Limnol. Oceanogr. 53, 456-468. doi: 10.4319/lo.2008.53.2.0456

Müller-Navarra, D. C., Brett, M. T., Liston, A. M., and Goldman, C. R. (2000). A highly unsaturated fatty acid predicts carbon transfer between primary producers and consumers. Nature 403, 74-77. doi: 10.1038/47469

Paerl, H. W., and Paul, V. J. (2012). Climate change: links to global expansion of harmful cyanobacteria. Water Res. 46, 1349-1363. doi: 10.1016/j.watres.2011.08.002

Park, S., Brett, M. T., Müller-Navarra, D. C., and Goldman, C. R. (2002). Essential fatty acid content and the phosphorus to carbon ratio in cultured algae as indicators of food quality for Daphnia. Freshw. Biol. 47, 1377-1390. doi: 10.1046/j.1365-2427.2002.00870.x

Peltomaa, E., Ojala, A., Holopainen, A.-L., and Salonen, K. (2013). Changes in phytoplankton in a boreal lake during a 14 -year period. Boreal Environ. Res. $18,387-400$.

R development Core Team (2017). R: A Language and Environment for Statistical Computing. Vienna: R Foundation for Statistical Computing. Available online at: https://www.R-project.org/

Ravet, J. L., and Brett, M. T. (2006). A comparison of phytoplankton phosphorus and essential fatty acid food quality constraints on Daphnia somatic growth and egg production. Limnol. Oceanogr. 51, 2438-2452. doi: 10.4319/lo.2006.51.5.2438

Ravet, J. L., Brett, M. T., and Arhonditsis, G. B. (2010). The effects of seston lipids on zooplankton fatty acid composition in Lake Washington. Ecology 91, 180-190. doi: 10.1890/08-2037.1

Ravet, J. L., Brett, M. T., and Müller-Navarra, D. C. (2003). A test of the role of polyunsaturated fatty acids in phytoplankton food quality for Daphnia using liposome supplementation. Limnol. Oceanogr. 48, 1938-1947. doi: 10.4319/lo.2003.48.5.1938

Rengefors, K., and LeGrand, C. (2001). Toxicity in Peridinium aciculiferum - an adaptive strategy to outcompete other winter phytoplankton? Limnol. Oceanogr. 46, 1990-1997. doi: 10.4319/lo.2001.46.8.1990

Reynolds, C. S. (2006). Ecology of Phytoplankton. Cambridge: Cambridge University Press.

Schindler, D. W. (1998). Sustaining aquatic ecosystems in boreal regions [online]. Conserv. Ecol. 2:18. Available online at: http://www.consecol.org/vol2/iss2/ art18/

Simopoulos, A. P. (2008). The importance of the omega-6/omega-3 fatty acid ratio in cardiovascular disease and other chronic diseases. Exp. Biol. Med. 233, 674-688. doi: 10.3181/0711-MR-311

Sterner, R. W., and Elser, J. J. (2002). Ecological Stoichiometry: the Biology of Elements from Molecules to the Biosphere. Princeton, NJ: Princeton University Press.

Sterner, R. W., and Schultz, K. L. (1998). Zooplankton nutrition: recent progress and a reality check. Aquat. Ecol. 32, 261-279. doi: 10.1023/A:1009949400573

Sukenik, A., Quesada, A., and Salmaso, N. (2015). Global expansion of toxic and non-toxic cyanobacteria: effect on ecosystem functioning. Biodivers. Conserv. 24, 889-908. doi: 10.1007/s10531-015-0905-9

Taipale, S. J., Brett, M. T., Hahn, M. W., Martin-Creuzburg, D., Yeung, S., Hiltunen, M., et al. (2014). Differing Daphnia magna assimilation efficiencies for terrestrial, bacterial, and algal carbon and fatty acids. Ecology 95, 563-576. doi: 10.1890/13-0650.1 
Taipale, S. J., Hiltunen, M., Vuorio, K., and Peltomaa, E. (2016a). Suitability of phytosterols alongside fatty acids as chemotaxonomic biomarkers for phytoplankton. Front. Plant Sci. 7:212. doi: 10.3389/fpls.2016.00212

Taipale, S. J., Kainz, M. J., and Brett, M. T. (2011). Diet-switching experiments show rapid accumulation and preferential retention of highly unsaturated fatty acids in Daphnia. Oikos 120, 1674-1682. doi: 10.1111/j.1600-0706.2011. 19415.x

Taipale, S. J., Kainz, M. J., and Brett, M. T. (2015). A low $\omega-3: \omega-6$ ratio in Daphnia indicates terrestrial resource utilization and poor nutritional condition. $J$. Plankt. Res. 37, 596-610. doi: 10.1093/plankt/fbv015

Taipale, S. J., Strandberg, U., Peltomaa, E., Galloway, A. W. E., Ojala, A., and Brett, M. (2013). Fatty acid composition as biomarkers of freshwater microalgae: analysis of 37 strains of microalgae in 22 genera and in seven classes. Aquat. Microb. Ecol. 71, 165-178. doi: 10.3354/ame01671

Taipale, S. J., Vuorio, K., Strandberg, U., Kahilainen, K. K., Järvinen, M., Hiltunen, M., et al. (2016b). Lake eutrophication and brownification downgrade availability and transfer of essential fatty acids for human consumption. Environ. Int. 96, 156-166. doi: 10.1016/j.envint.2016.08.018

Turner, J. T. (2004). The importance of small planktonic copepods and their roles in pelagic marine food webs. Zool. Stud 43, 255-266.

Twining, C. W., Brenna, J. T., Hairston, N. G., and Flecker, A. S. (2016). Highly unsaturated fatty acids in nature: what we know and what we need to learn. Oikos 125, 749-760. doi: 10.1111/oik.02910

Urabe, J., and Watanabe, Y. (1992). Possibility of N or P limitation for planktonic cladocerans: an experimental test. Limnol. Oceanogr. 37, 244-251. doi: 10.4319/lo.1992.37.2.0244
Urabe, J., Clasen, J., and Sterner, R. W. (1997). Phosphorus limitation of Daphnia growth: is it real? Limnol. Oceanogr. 42, 1436-1443. doi: 10.4319/lo.1997.42.6.1436

van Donk, E., Lürling, M., Hessen, D. O., and Lockhorst, G. M. (1997). Altered cell wall morphology in nutrient-deficient phytoplankton and its impact on grazers. Limnol. Oceanogr. 42, 357-364. doi: 10.4319/lo.1997.42.2.0357

Vance, D. E., and Vance, J. E. (2008). Biochemistry of Lipids and Membranes. New York, NY: Benjamin Cummings Pub Co.

Venables, W. N., and Ripley, B. D. (2002). Modern Applied Statistics with S, 4th $E d n$. New York, NY: Springer.

von Elert, E. (2002). Determination of limiting polyunsaturated fatty acids in Daphnia galeata using a new method to enrich food algae with single fatty acids. Limnol. Oceanogr. 47, 1764-1773. doi: 10.4319/lo.2002.47.6.1764

Conflict of Interest Statement: The authors declare that the research was conducted in the absence of any commercial or financial relationships that could be construed as a potential conflict of interest.

The reviewer, CS, and handling Editor declared their shared affiliation.

Copyright $\odot 2017$ Peltomaa, Aalto, Vuorio and Taipale. This is an open-access article distributed under the terms of the Creative Commons Attribution License (CC BY). The use, distribution or reproduction in other forums is permitted, provided the original author(s) or licensor are credited and that the original publication in this journal is cited, in accordance with accepted academic practice. No use, distribution or reproduction is permitted which does not comply with these terms. 